\title{
Dye-Sensitized Solar Cell Based on a Three-Dimensional Photonic Crystal
}

\author{
Stefan Guldin, ${ }^{\dagger}$ Sven Hüttner, ${ }^{\dagger}$ Matthias Kolle, ${ }^{\dagger,}{ }^{\ddagger}$ Mark E. Welland, ${ }^{\ddagger}$ \\ Peter Müller-Buschbaum, ${ }^{\S}$ Richard H. Friend, ${ }^{\dagger}$ Ullrich Steiner, ${ }^{\dagger, l l}$ and Nicolas Tétreault*, ${ }^{*}, \neq, \perp$ \\ ${ }^{\dagger}$ Cavendish Laboratory, Department of Physics, University of Cambridge, J J Thomson Avenue, \\ Cambridge CB3 OHE, U.K., ${ }^{*}$ Nanoscience Centre, University of Cambridge, $11 \mathrm{~J} \mathrm{~J} \mathrm{Thomson} \mathrm{Avenue,}$ \\ Cambridge CB3 OFF, U.K., ${ }^{\S}$ Physik Department, Technische Universität München, James-Franck-Strasse 1, \\ 85747 Garching, Germany, and "Freiburg Institute for Advanced Studies (FRIAS), Universität Freiburg, Albertstrasse 19, \\ D-79104 Freiburg, Germany
}

\begin{abstract}
We present a material assembly route for the manufacture of dye-sensitized solar cells, coupling a high-surface mesoporous layer to a three-dimensional photonic crystal (PC). Material synthesis aided by self-assembly on two length scales provided electrical and pore connectivity at the mesoporous and the microporous level. This construct allows effective dye sensitization, electrolyte infiltration, and charge collection from both the mesoporous and the PC layers, opening up additional parameter space for effective light management by harvesting PC-induced resonances.
\end{abstract}

KEYWORDS Photonic crystal, self-assembly, photovoltaics, dye-sensitized solar cell

E ver since the pioneering work of O‘Regan and Grätzel, dye-sensitized solar cells (DSCs) have attracted great interest as a promising technology for future sustainable energy generation. ${ }^{1}$ In DSCs, charge carrier generation takes place in a chemisorbed monolayer of photoactive dye which is sandwiched between a semiconductor oxide, usually mesoscopic anatase, and an electrolyte acting as electron and hole conducting materials, respectively. Using state-of-the-art ruthenium-based inorganic dyes, efficiencies higher than $11 \%$ have been reported. ${ }^{2-4}$ DSCs are generally made from cheap and nontoxic components and can be designed in a variety of different colors and transparencies, which distinguishes them as an ideal photovoltaic concept for integrated architecture. It therefore seems only a matter of time before large scale production will follow. ${ }^{5}$

In general, improvements in the overall power conversion efficiency have been centered on increasing the photovoltage through manipulation of the oxide, improving the photocurrent with new dyes, and increasing stability by better encapsulation. ${ }^{5}$ While record-holding liquid electrolyte DSCs already achieve maximum quantum efficiency (photon-toelectron conversion) in the spectral range around $520 \mathrm{~nm}$, light harvesting in the red and near-infrared (at the tail of the absorption spectra) is still relatively low. In solid-state devices, light absorption is generally limited by the film thickness, as thick mesoporous films prove difficult to infil-

\footnotetext{
* To whom correspondence should be addressed, nicolas.tetreault@epfl.ch.

${ }^{\perp}$ Current address: Laboratory of Photonic and Interfaces, EPFL, Lausanne, Switzerland.

Received for review: 07/30/2009

Published on Web: 05/27/2010
}

trate. ${ }^{6}$ One way to successfully enhance light harvesting is the introduction of optical elements, such as highly scattering layers. These consist of large particles, that increase the photon path length in the cell..$^{7,8}$ This ubiquitous approach has the unfortunate effect of rendering the DSC opaque thus depriving it of one of its main advantages over competing technologies. As a result, photonic band gap materials in the form of 3D inverted $\mathrm{TiO}_{2}$ opal or porous bragg stacks have been applied to DSCs to enhance light harvesting in specific parts of the spectrum while retaining the cell transparency. ${ }^{9-12}$ Several theoretical approaches report a variety of possible effects, including the localization of heavy photons near the edges of a photonic bandgap, ${ }^{13}$ Bragg diffraction in a periodic lattice, ${ }^{14}$ multiple scattering at disordered regions in the photonic crystal (PC), ${ }^{15}$ and the formation of multiple resonant modes. ${ }^{16}$ The latter effect predicted by Mihi and Miguez $^{16}$ by a scalar wave approximation has generated interest as it promises significant enhancement over a large part of the spectrum. According to these calculations, resonant cavities which are determined by the penetration depth of the incoming light and the thickness of the mesoporous film between the PC and the substrate give rise to photon localization in the cell and therefore a much higher probability of photon absorption.

The main challenges when assembling a functioning double layer device is to grow a 3D self-assembled polystyrene opal structure of high optical quality onto a previously deposited mesoporous $\mathrm{TiO}_{2}$. The colloidal array has to be subsequently infiltrated with high refractive index material, typically $\mathrm{TiO}_{2}$, without clogging the mesoscopic pores of the underlayer which would inhibit sensitization and electrolyte infiltration of the double layer device. In early approaches, 
PC layers could only be deposited directly on the transparent electrode rather than on top of a mesoporous $\mathrm{TiO}_{2}$ layer. ${ }^{9,10}$ In order to minimize direct back-reflection of the incident photons, the cells had to be illuminated from the backside of the device, leading to a significant loss due to absorption in the platinum counter-electrode and the excess path length through the electrolyte. ${ }^{17}$ Miguez and co-workers proposed that resonant modes covering a large part of the spectrum can only be exploited if the mesoporous $\mathrm{TiO}_{2}$ layer was positioned in between the PC and the conductive substrate. ${ }^{18}$ This was attempted in several studies. ${ }^{11,19}$ Recently, Lee et al. presented a new material route which enabled the beneficial layer sequence by infiltrating and thereby protecting the mesoporous underlayer with a block copolymer. ${ }^{20}$ They subsequently characterized the effect of such a double layer structure in great detail. They found, however, that their material lacked the intimate physical contact between the nanoporous $\mathrm{TiO}_{2}$ and $\mathrm{TiO}_{2}$ inverse opal layers that is needed to achieve resonant modes. Furthermore, poor coupling of the two layers prevented charge carriers generated in the inverse opal layer to contribute to the overall photocurrent. Their study emphasizes the need for an approach for the simultaneous deposition of mesoporous titania and the pore protective material to prevent pore clogging and enabling direct pore and electrical contact between the layers.

Since 1997, amphiphilic copolymers have been successfully used to obtain customized nanostructures of a variety of inorganic materials such as silica or metal oxides. ${ }^{21,22}$ The general idea of this bottom-up approach is the following: a nanoparticle $(1-4 \mathrm{~nm})$ sol of the desired oxide $\left(\mathrm{SiO}_{2}, \mathrm{TiO}_{2}\right.$, $\mathrm{Nb}_{2} \mathrm{O}_{5}$, etc.) is mixed with a block copolymer, consisting of two or more incompatible building blocks. As the solvent evaporates, the block-copolymer self-assembles through microphase separation. The topology and dimensions of this self-assembled structure depend on the relative volume ratios of the polymer blocks and the overall chain length. The range of possible morphologies includes micellar, lamellar, hexagonal, and gyroid mesostructures. ${ }^{21,23}$ Inorganic nanoparticles take part in the microphase separation process if they preferentially interact with one of the building blocks. The copolymer morphology is finally reflected in the resulting inorganic mesostructure after calcination. The main benefit of these materials for DSC manufacture is their continuous mesoporous network, offering long-range order, high surface area, and potentially increased electron mobility. ${ }^{24-28}$ The latter is a great advantage in new generation solid state DSCs where the recombination rate is higher and pore filling can be problematic. ${ }^{29,30}$ Even though some of these constructs suffer from a significantly lower surface area and, thus, reduced light harvesting, they do offer a direct charge extraction pathway which results in higher electron lifetime and a lower recombination rate. ${ }^{31,32}$

Here, we present a material assembly route for a double layer DSC, integrating a high surface mesoporous underlayer with an optically active 3D photonic crystal (PC) overlayer. Self-assembly material synthesis on two length-scales enabled us to fabricate a double layer DSC with electric and pore connectivity at the mesoporous and the microporous level. This construct allows effective dye sensitization, electrolyte infiltration, and charge collection from both the mesoporous and the PC layers. Due to the intimate physical contact between the layers, photonic crystal-induced resonances can significantly contribute to absorption enhancement in a specific part of the spectrum.

A schematic representation of the fabrication method for a double layer self-assembled DSC is shown in Figure 1. For the synthesis of the copolymer-derived mesoporous underlayer a solution is prepared in the following way: a sol containing the titanium precursor is obtained by rapidly adding $0.69 \mathrm{~mL}$ of $\mathrm{HCl}(37 \%$, BASF) into $1 \mathrm{~mL}$ of titanium ethoxide (purum, Fluka) under vigorous stirring. ${ }^{33}$ A 0.873 $\mathrm{mL}$ portion of the resulting sol is then mixed with $0.1 \mathrm{~g}$ of polyisoprene-block-poly(ethylene oxide) copolymer (PI-bPEO) $\left(M_{\mathrm{n}}=35.7 \mathrm{~g} / \mathrm{mol}, 23 \mathrm{wt} \% \mathrm{PEO},{ }^{34}\right)$ in $7 \mathrm{~mL}$ of tetrahyfrofuran (THF, $99.97 \%$, Fisher). The solution is poured into a Petri dish at $50^{\circ} \mathrm{C}$. Shortly after solvent evaporation, the dry material is redissolved in an azeotrope mixture of toluene (apolar, 99,8\%, Fisher) and 1-butanol (polar, 99\%, Aldrich). This step is necessary to eliminate the significant amount water and ethanol (over $70 \mathrm{wt} \%$ ) from the hydrolytic sol, which is found to be detrimental for the simultaneous and continuous evaporation of the hydrophobic and hydrophilic components during thin film processing. The 20 wt \% solution is then spin-coated ( $5 \mathrm{~s}, 1500 \mathrm{rpm}$ ) and dried for several hours at room temperature. Residual solvent is subsequently evaporated by heating the samples in a tube furnace at $130^{\circ} \mathrm{C}$ for $1 \mathrm{~h}$. Finally, a thin overlayer is removed using directional reactive ion etching $\left(\mathrm{CF}_{4}, 2 \mathrm{~min}, 50 \mathrm{~W}, 16\right.$ mbar, $3.56 \mathrm{MHz}, 310 \mathrm{~V}$, homebuild system). This diblock copolymer $-\mathrm{TiO}_{2}$ layer provides a suitable substrate for the evaporation-induced self-assembly of polystyrene spheres. ${ }^{35}$ In this study suspensions of three different sphere diameters $240 \mathrm{~nm}$ (PC1, Ikerlat), $260 \mathrm{~nm}$ (PC2, Ikerlat), and $350 \mathrm{~nm}$ (PC3, Polybead) are used. For PC1 and PC3, a 0.5 vol \%, for PC2 a 1 vol \% suspension of monodispersed polystyrene spheres is dispersed in ethanol into which the film-covered substrate is inserted vertically. Upon solvent evaporation, a uniform face-centered-cubic (fcc) colloidal PC template is formed on the film. This three-dimensional template is then infiltrated using a binary atmospheric pressure chemical vapor deposition (APCVD) technique published elsewhere. ${ }^{36}$ Briefly, the template is heated to $80{ }^{\circ} \mathrm{C}$ before being subjected to water vapor and then to titanium tetrachloride vapor in alternating cycles to form amorphous $\mathrm{TiO}_{2}$. Since the hybrid underlayer is nonporous, the APCVD of $\mathrm{TiO}_{2}$ does not clog the pores of the underlying $\mathrm{TiO}_{2}$ mesostructure, which would hinder sensitization and electrolyte infiltration. The samples are exposed to another cycle of reactive ion etching $\left(\mathrm{CF}_{4}, 5 \mathrm{~min}\right.$ see conditions above) to remove the 
(a)
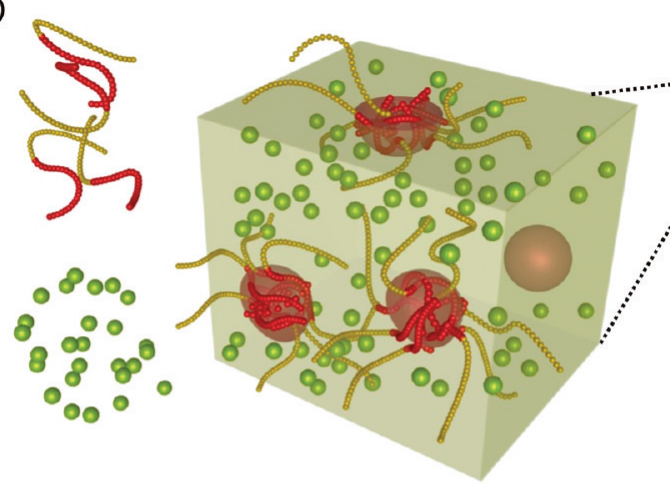

(e)

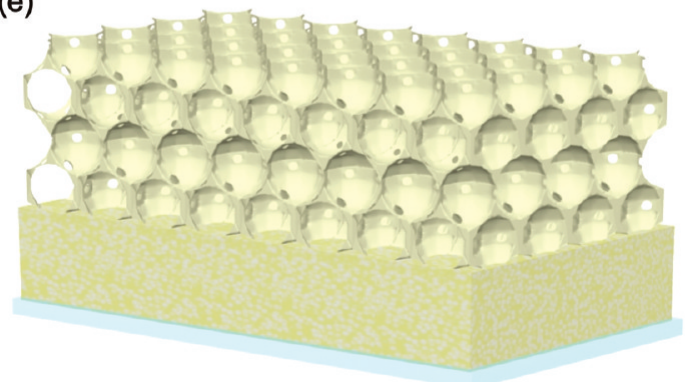

(b)

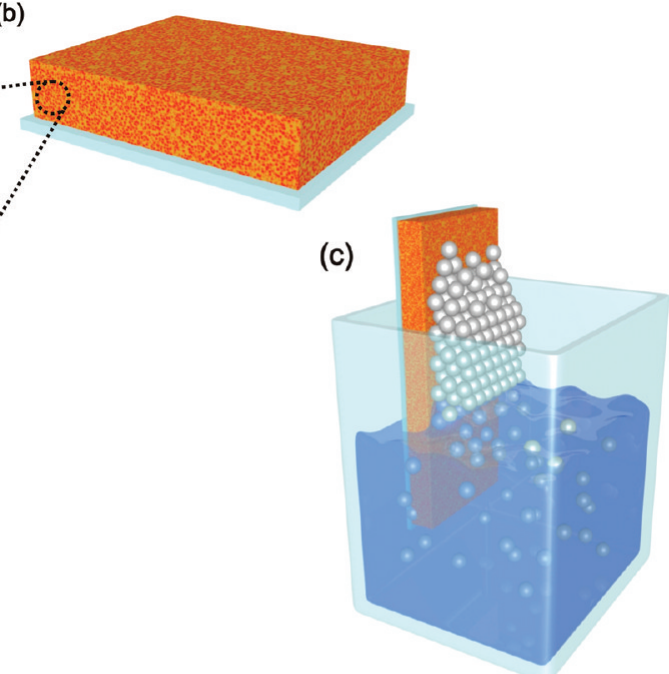

(d)

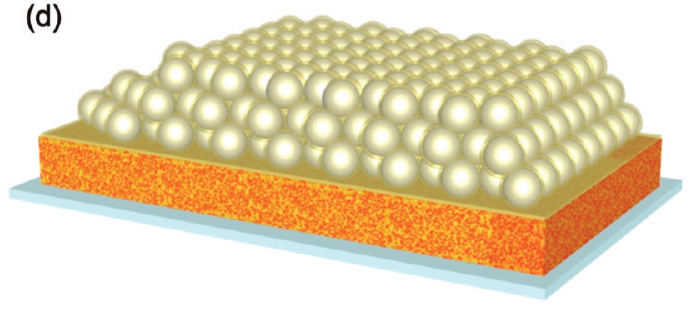

FIGURE 1. Schematic of double layer assembly. (a) A solution of PI- $b$-PEO copolymer and $1-4 \mathrm{~nm} \mathrm{TiO}_{2}$ nanoparticles is (b) codeposited on a FTO-covered glass substrate by spin-coating and solvent evaporation. (c) The covered substrate is placed vertically in an ethanolic suspension of polystyrene microspheres to induce the self-assembly of the 3D PC template. (d) APCVD of amorphous $\mathrm{TiO}_{2}$ into the interstitial pores of the polystyrene template. (e) High temperature annealing reveals the double layer $\mathrm{TiO}_{2}$ photoanode with full pore and electronic connectivity.

(a)

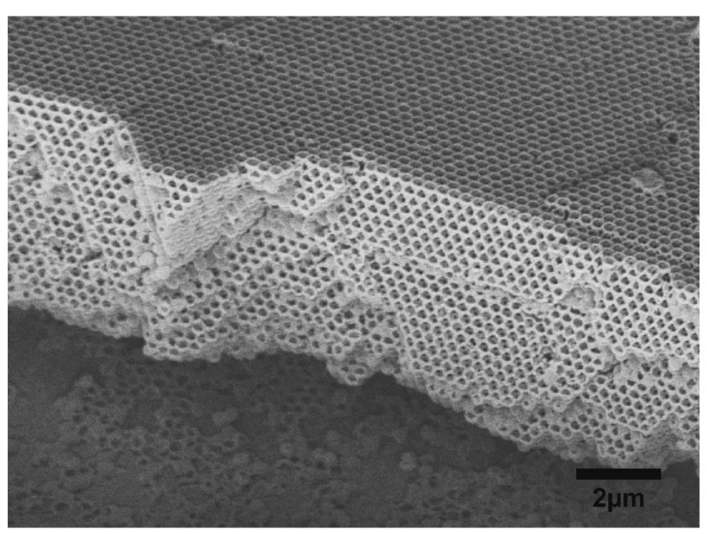

(b)

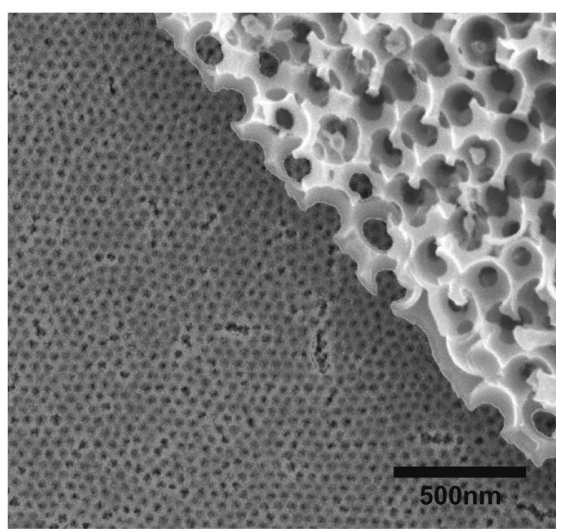

FIGURE 2. SEM cross-sectional micrographs of (a) the inversed $\mathrm{TiO}_{2}$ opal PC on top of a mesoscopic $\mathrm{TiO}_{2}$ underlayer after high temperature annealing and (b) high-resolution micrograph showing complete pore connectivity between mesopores and micropores.

excess of deposited material on the colloidal crystal $( \pm 15$ $\mathrm{nm})$. The double layer is then heated to $500{ }^{\circ} \mathrm{C}(3 \mathrm{~h}$, heat ramp $\left.1{ }^{\circ} \mathrm{C} / \mathrm{min}\right)$ to burn off the organic material from the diblock copolymer underlayer and the polystyrene colloidal template and to crystallize the $\mathrm{TiO}_{2}$.

For device characterization, standard liquid electrolyte DSCs are assembled using the N719 ruthenium-based sensitizer as reported elsewhere. ${ }^{37,38}$
Scanning electron micrographs of an annealed double layer photoanode synthesized are presented in Figure 2. These confirm the successful self-assembly of a 3D fcc polystyrene PC template on top of the hybrid thin film and the subsequent APCVD infiltration with $\mathrm{TiO}_{2}$. After calcination, the polymers in both layers are burned off to reveal the mesoscopic and microscopic pores in the underlayer and $\mathrm{PC}$, respectively. The mesoscopic layer thickness is $465 \pm$ 
(a)

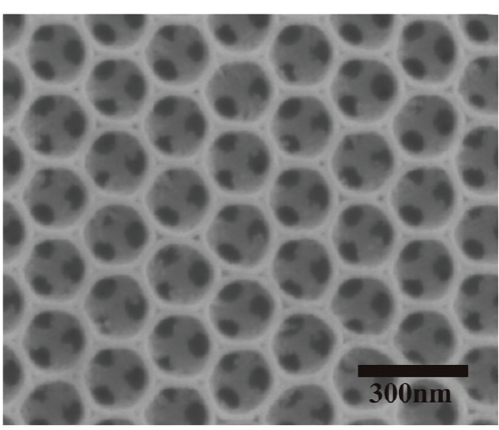

(c)

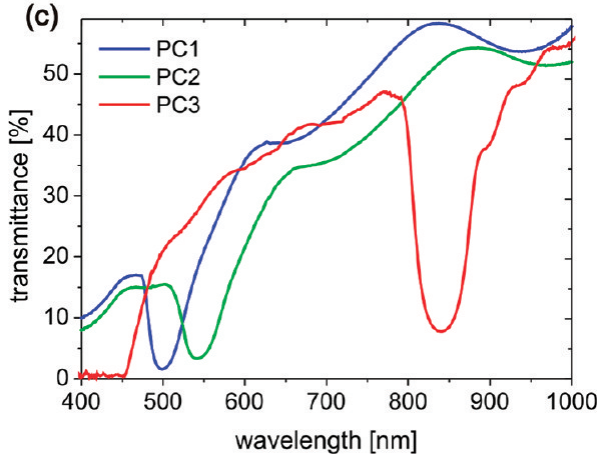

(b)

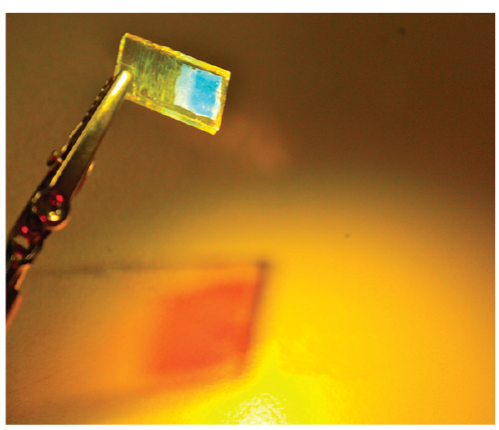

(d)

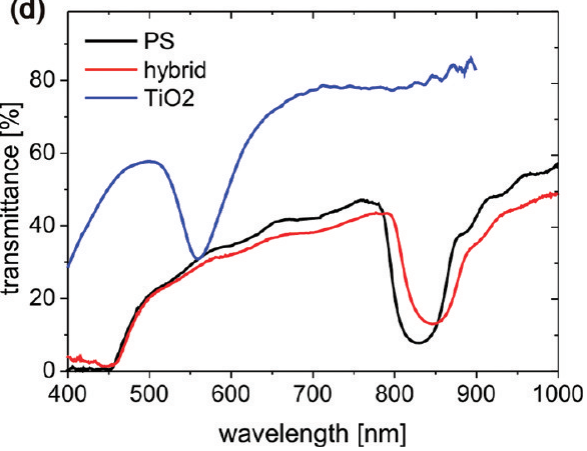

FIGURE 3. (a) SEM micrograph showing the (111) top surface of the resulting inverse $\mathrm{TiO}_{2}$ opal PC1. (b) $\mathrm{Photograph}$ of a TiO $\mathrm{P}_{2}$ double layer with PC3. (c) UV-vis transmittance spectrum of the colloidal PC templates for PC1 (blue, $240 \mathrm{~nm}$ ), PC2 (green, $260 \mathrm{~nm}$ ), and PC3 (red, $350 \mathrm{~nm}$ ). (d) Transmission spectrum of the PC3 sample for the different stages of the fabrication process: PS colloidal array in air (black), infiltrated template (red), and $\mathrm{TiO}_{2}$ inverse opal in air after calcination (blue).

$30 \mathrm{~nm}$ (determined by film profilometry) while the PC thickness is about 10 colloidal layers for PC 1 and PC 3 and 20 colloidal layers for PC2 (by SEM). The pore connectivity between both layers is visible in Figure $2 \mathrm{~b}$ confirming that the fabrication method provides an effective protection for the mesopores from the APCVD process used to fill the PC template. This important characteristic enables effective dye sensitization of the high surface area mesoscopic underlayer as well as the unhindered electrolyte infiltration throughout the photoanode. Finally, we find the APCVD infiltration to be uniform throughout the crystal with no evidence of delamination from the PC overlayer.

Figure 3 a shows the top surface of the (111) crystal plane of the inverted $\mathrm{TiO}_{2} \mathrm{PC}$ layer obtained after deposition of $240 \mathrm{~nm}$ PS spheres, APCVD, $\mathrm{CF}_{4}$ etching of the $\mathrm{TiO}_{2}$ overlayer, and high-temperature annealing. Figure $3 \mathrm{~b}$ shows a photograph of a $\mathrm{TiO}_{2}$ double layer (PC3). Note the complementary colors of the reflected and transmitted light. In Figure $3 \mathrm{c}$ the optical transmission spectrum through the selfassembled fcc PC template is shown for all three diameters used in this study. The transmission dips at 500, 540, and $825 \mathrm{~nm}$ for PC1, PC2, and PC3 correspond to the Bragg reflection peaks for the (111) $\Gamma$-L pseudogap of fcc crystals of PS spheres with diameters of 210,227, and $350 \mathrm{~nm}$, respectively $\left(n_{\text {eff }}=1.46\right.$ ). In Figure $3 d$ the transmission spectrum for the different stages of the fabrication process is shown for PC3. After infiltration of the colloidal array with amorphous titania, the transmission dip shifts to $850 \mathrm{~nm}$.
The lattice contracts upon calcination and crystallization of the $\mathrm{TiO}_{2}$, leading to a titania inverse opal with $240 \mathrm{~nm}$ pores and a refractive index $n_{\mathrm{TiO}_{2}}$ of $\approx 2.3$, yielding the corresponding $\mathrm{TiO}_{2}$ transmission spectrum in air. From these measurements, we find that the presented fabrication method produces high-quality photonic crystal structures with the expected optical characteristics.

In order to reveal the significance of the PC top layer for light harvesting, the photon-to-electron (EQE) conversion behavior of double layer DSCs were compared to a single layer reference. For this study, a relatively thin $\mathrm{TiO}_{2}$ underlayer (465 $\pm 30 \mathrm{~nm}$ ) was chosen to avoid the formation of cracks which do appear in films thicker than about $1 \mu \mathrm{m}$ and which give rise to light scattering. We have shown in earlier studies that the surface area of mesoporous polymer derived $\mathrm{TiO}_{2}$ is strongly influenced by the crystallite size. ${ }^{39}$ On the basis of this earlier study, a double layer device consisting of a $465 \mathrm{~nm}$ underlayer with $32 \%$ porosity and a $1.4 \mu \mathrm{m}$ PC top layer with $78 \%$ porosity have the same calculated specific surface area as an approximately $900 \mathrm{~nm}$ thick single mesoporous film, which was therefore used as a reference.

For all EQE measurements, a $1 \mathrm{~mm}^{2}$ surface was illuminated from the FTO side with an intensity of $100 \mathrm{~mW} /$ $\mathrm{cm}^{2}$ (AM 1.5). The EQE characteristics of the three PC cell types are shown in Figure 4. Two main characteristics of the double layer devices are apparent in the EQE and normalized EQE spectra. First, double layer devices with a compa- 
(a)

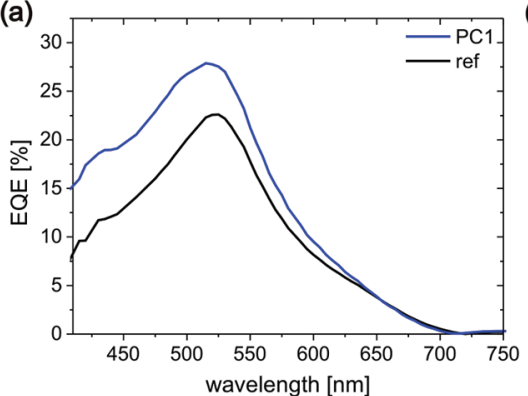

(d)

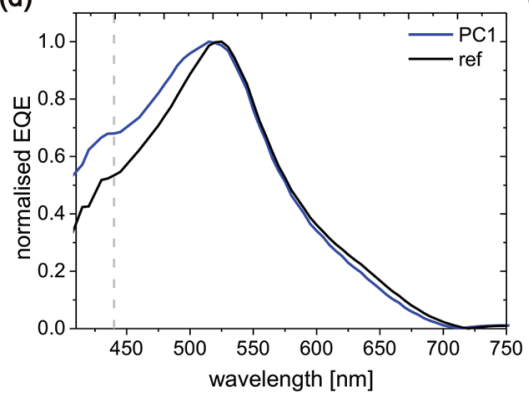

(b)

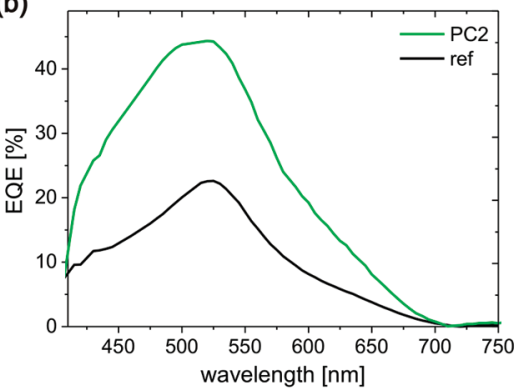

(e)

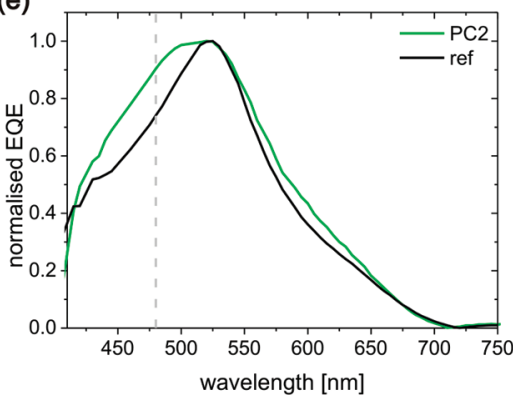

(c)

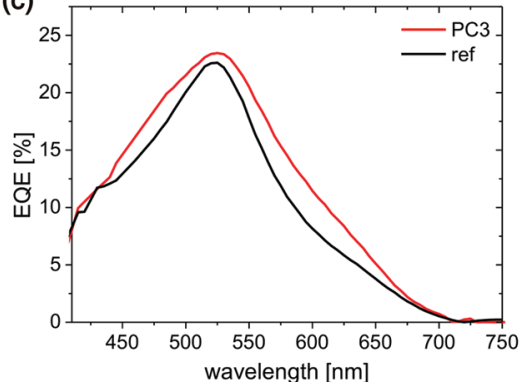

(f)

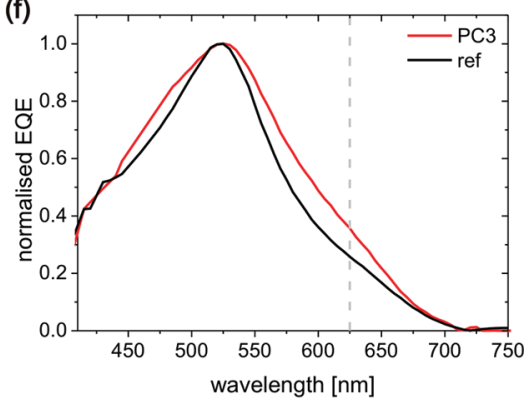

FIGURE 4. $(\mathrm{a}-\mathrm{c}) \mathrm{EQE}$ of devices with photonic crystal top layers compared to a single layer reference device. The available surface area of devices PC1 (a, blue) and PC3 (c, red) are comparable to the surface area of a $900 \mathrm{~nm}$ thick mesoporous single layer device (a-c, black). PC2 (b, green) has a PC of double thickness coupled to the $465 \mathrm{~nm}$ thick underlayer and therefore significantly more surface area. (d-f) Relative spectral EQE of the different cell types normalized at a wavelength of $520 \mathrm{~nm}$. The gray dashed line indicates the calculated Bragg position in the liquid electrolyte DSC $\left(n_{\mathrm{TiO}_{2}}=2.3, n_{\text {electrolyte }}=1.34\right)$.
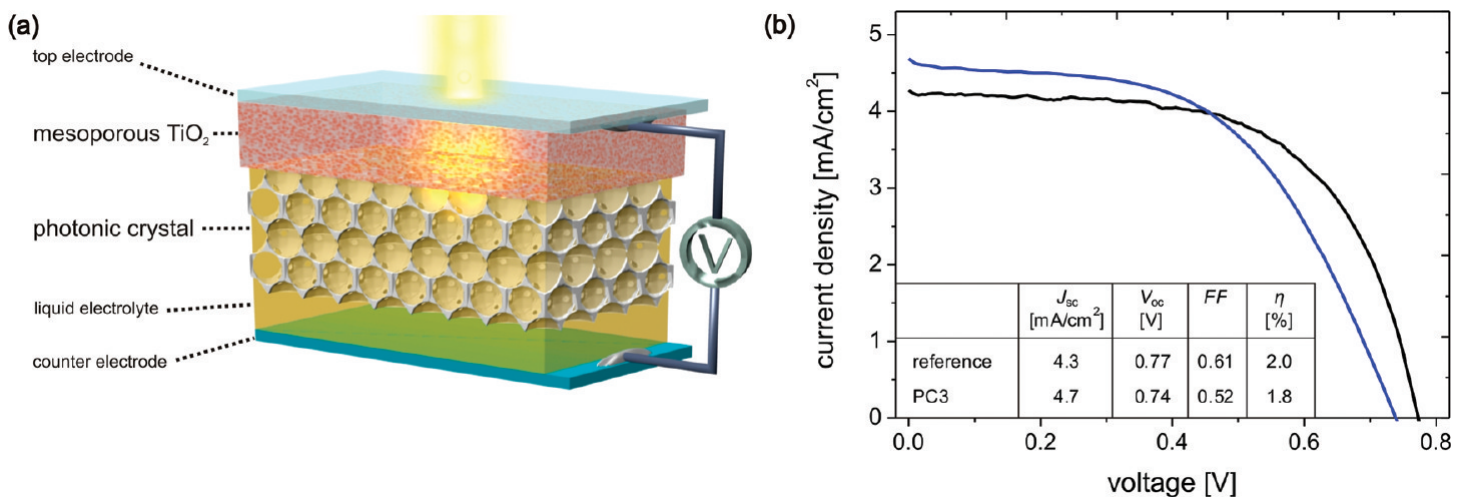

FIGURE 5. (a) Schematic of a fully assembled DSC based on the self-assembled double layer photoanode. (b) Current-voltage characteristics of the double layer device PC3 (blue) and a reference single layer cell of similar internal surface area (black) under standardized AM 1.5 illumination of $100 \mathrm{~mW} / \mathrm{cm}^{2}$ (active area $0.13 \mathrm{~cm}^{2}$, spectral mismatch $22 \%$ ).

rable surface area to that of the single layer reference are found to have comparable peak absorption values in the measured spectral range, as seen for PC1 (a) and PC3 (c). In contrast, PC2 has a significantly thicker PC top layer $(\approx 3 \mu \mathrm{m})$ and, therefore, a roughly $40 \%$ higher surface area when compared to the double layer devices PC1 or PC2 or the reference cell. The fact that the EQE is increased accordingly supports our assertion that the PC top layers are electrically connected and contribute to light harvesting over the entire measured spectrum.

When normalized to the EQE maxima in Figure $5 \mathrm{~d}-\mathrm{f}$ the significance of a PC top layer for spectrally selective light harvesting is revealed. From the observed pore sizes of the inverse opal structures for PC1 (160 nm diameter), for PC2
$(180 \mathrm{~nm})$, and for PC3 $(240 \mathrm{~nm})$, we calculate their respective Bragg peak position in electrolyte at about 440, 480, and $625 \mathrm{~nm}$, respectively.

In earlier studies, Mallouk and co-workers identified defect scattering as the main reason for the enhancement in relative photon-to-electron conversion efficiency. ${ }^{10,20}$ However, the theoretical work by Usami shows that random scattering in DSCs should most efficiently occur at $\lambda \approx 1.33 d$, where $d$ is the diameter of the scattering object. ${ }^{40}$ For our feature sizes, random scattering would therefore occur in the deep blue of the spectrum. Furthermore, Rengarajan et al. concluded that scattering from defect planes in PCs decreases significantly with a decreasing ratio of $d_{\text {opal }} / \lambda$, leading to very low scattering probabilities in the red for our feature 
sizes. ${ }^{15}$ Because of the low long-wavelength absorption of the dye, increasing the overall thickness of the photoactive layer will lead to a slight relative increase of red absorption. This small effect is visible in Figure $4 \mathrm{e}$ at a wavelength region around $600 \mathrm{~nm}$, caused by the larger thickness of the PC2 layer compared to PC1 and PC3. The substantially increased EQE in the red for the PC3 cell in Figure 4f, on the other hand, arises from the PC resonance at $625 \mathrm{~nm}$.

All three PC samples show a relative increase in absorption in the blue, which suggests a contribution to the absorption enhancement from scattering. We find, however, that the shape of the normalized EQE spectra shifts for PC1, PC2, and PC3 compared to the reference. Increased absorption is seen in the region of the calculated $\Gamma-L$ pseudo-band-gap of the PC and cannot solely be attributed to random defectbased scattering. Finally, the enhancement is found in a wider spectral region than is expected in the case of slow photon propagation modes at the red edge of the photonic band gap. ${ }^{13}$

Our results are in accordance with results of a recent experimental study by Lee et al. who identified three main effects at different spectral regions for the increase in photocurrent in double layer DSCs: ${ }^{20}$ (1) multidirectional scattering of short wavelength photons due to defects in the PC layer, ${ }^{10}(2)$ back reflection of light in the stop band region of the PC due to the PC layer acting as a dielectric mirror, and (3) an absorption enhancement caused by resonant modes as predicted by Mihi and Míguez. ${ }^{16}$

Lee et al.'s approach of adding a photonic crystal top layer has resulted, however, only in a weak shift of the absorption properties due to the photonic structure which they assigned to a lack of physical contact between the layers and a rough interface. ${ }^{20}$ In contrast, our straightforward fabrication method provides for close contact and a smooth interface between the mesoporous titania and the photonic crystal. This enables a significant enhancement in specific parts of the action spectrum as well as additional charge carrier generation arising from the photoactive material of the photonic crystal, which is now a functional part of the DSC.

Figure 5a shows a schematic of a fully assembled DSC based on the self-assembled double layer photoanode. I-V measurements of the cell types were carried out under standardized AM1.5 illumination of $100 \mathrm{~mW} / \mathrm{cm}^{2}$ (active area $0.13 \mathrm{~cm}^{2}$, spectral mismatch $22 \%$ ). In Figure $5 \mathrm{~b}$ the $J-V$ curves are shown for the double layer PC3 device in comparison to a reference cell. The PC3 exhibits a $10 \%$ increase in photocurrent $J_{\mathrm{sc}}$ of $4.7 \mathrm{~mA} / \mathrm{cm}^{2}$ compared to the reference of $4.3 \mathrm{~mA} / \mathrm{cm}^{2}$, which is in agreement with the EQE measurements of Figure 4c. The double layer device exhibits, however, a slightly lower open circuit potential $V_{\text {oc }}$ $(0.74 \mathrm{~V}$ vs. $0.77 \mathrm{~V})$ and a $15 \%$ decrease in fill factor $F F(0.52$ vs. 0.61) which results in an overall decrease in conversion efficiency to $\eta 1.8 \%$ from $2.0 \%$ of the reference cell. Miguez and co-workers recently pointed out that very thick inverse opal films $(>5 \mu \mathrm{m})$ are likely to have an adverse effect on charge transport and recombination through the cell, which results in a penalty in both the photovoltage and the photocurrent under real operation conditions. ${ }^{41}$ The present study reveals only a slight decrease in fill factor for double layer devices. Further device characterization is currently ongoing, which will ultimately lead to an optimized device design with improved performance.

In conclusion, we present a fabrication method for a dye-sensitized solar cell architecture, which couples a high surface area mesoporous anatase underlayer with an optically and electrically active three-dimensionally periodic $\mathrm{TiO}_{2} \mathrm{PC}$ overlayer. In contrast to earlier studies the double layer structure exhibits porosity at the mesoporous and the microporous length scales as well as pore and electronic connectivity at all levels. This construct enables effective dye sensitization, electrolyte infiltration and charge collection from both the mesoporous and the PC layers. Due to the smooth layer interface and the direct physical and electronic contact between the layers, light harvesting in specific parts of the spectrum was significantly increased by exploiting PC-induced resonances. Further investigation of its device photovoltaic characteristics, including charge mobility and recombination rates as well as optimization of the PC structure, is needed to fully exploit the EQE increase. This approach for the first time fully integrates a PC top layer into a functioning DSC, opening up an additional parameter space for effective light management. Finally, since the integration of an electrically and optically active PC increases the absolute photon-to-electron conversion efficiency and broadens the light harvesting capability of DSCs, this approach should be useful in solid-state devices where pore infiltration is a limiting factor ${ }^{42}$ as well as in weakly absorbing organic photovoltaic devices. ${ }^{43}$

Acknowledgment. Funding though the EPSRC Nanotechnology Grand Challenges: Energy programme (EP/F056702/1) is gratefully acknowledged. N.T. would like to thank EPSRC (RG 432863 KJZA/051) for funding. S.G. is grateful to Studienstiftung des deutschen Volkes for funding. We thank Professor U. Wiesner and C. Orilall for supplying the block copolymer and Dr. H. Snaith for the useful discussions.

\section{REFERENCES AND NOTES}

(1) O’Regan, B.; Gratzel, M. Nature 1991, 353, 737-740.

(2) Chiba, Y.; Islam, A.; Watanabe, Y.; Komiya, R.; Koide, N. Jpn. J. Appl. Phys., Part 22006.

(3) Gao, F.; Wang, Y.; Shi, D.; Zhang, J.; Wang, M.; Jing, X. J. Am. Chem. Soc. 2008

(4) Graetzel, M. Prog. Photovoltaics 2006, 14, 429-442.

(5) Kroon, J. M.; et al. Prog. Photovoltaics 2007, 15, 1-18.

(6) Ding, I.-K.; Tetreault, N.; Brillet, J.; Hardin, B. E.; Smith, E. H.; Rosenthal, S. J.; Sauvage, F.; Graetzel, M.; McGehee, M. D. Adv. Funct. Mater. 2009, 19, 2431-2436.

(7) Hore, S.; Vetter, C.; Kern, R.; Smit, H.; Hinsch, A. Sol. Energy Mater. Sol. Cells 2006, 90, 1176-1188.

(8) Ferber, J.; Luther, J. Sol. Energy Mater. Sol. Cells 1998, 54, 265275 .

(9) Nishimura, S.; Abrams, N.; Lewis, B.; Halaoui, L. J. Am. Chem. Soc. 2003. 
(10) Halaoui, L.; Abrams, N.; Mallouk, T. J. Phys. Chem. B 2005, 109 6334-6342.

(11) Mihi, A.; Calvo, M. E.; Anta, J. A.; Miguez, H.J. Phys. Chem. C 2008 $112,13-17$

(12) Colodrero, S.; Mihi, A.; Haggman, L.; Ocana, M.; Boschloo, G.; Hagfeldt, A.; Míguez, H. Adv. Mater. 2009, 21, 764.

(13) Sakoda, K. Opt. Express 1999, 4, 167-176.

(14) Mittleman, D.; Bertone, J.; Jiang, P.; Hwang, K.; Colvin, V.J. Chem. Phys. 1999, 111, 345-354.

(15) Rengarajan, R.; Mittleman, D.; Rich, C.; Colvin, V. Phys. Rev. E 2005, 71, 15968-15976.

(16) Mihi, A.; Miguez, H.J. Phys. Chem. B 2005, 109, 15968-15976

(17) Ito, S.; Zakeeruddin, S. M.; Comte, P.; Liska, P.; Kuang, D.; Graetzel, M. Nat. Photonics 2008, 2, 693-698

(18) Mihi, A.; Lopez-Alcaraz, F.; Miguez, H. Appl. Phys. Lett. 2006, 88, 193110

(19) Pozas, R.; Mihi, A.; Ocana, M.; Miguez, H. Adv. Mater. 2006, 18 1183.

(20) Lee, S.-H. A.; Abrams, N. M.; Hoertz, P. G.; Barber, G. D.; Halaoui, L. I.; Mallouk, T. E. J. Phys. Chem. B 2008, 112, 14415-14421.

(21) Templin, M.; Franck, A.; DuChesne, A.; Leist, H.; Zhang, Y.; Ulrich, R.; Schadler, V.; Wiesner, U. Science 1997, 278, 1795-1798.

(22) Yang, P.; Zhao, D.; Margolese, D.; Chmelka, B.; Stucky, G. Nature 1998, 396, 152-155

(23) Simon, P.; Ulrich, R.; Spiess, H.; Wiesner, U. Chem. Mater. 2001, 13, 3464-3486.

(24) Zukalova, M.; Zukal, A.; Kavan, L.; Nazeeruddin, M.; Liska, P.; Grtzel, M. Nano Lett. 2005, 5, 1789-1792.

(25) Fattakhova-Rohlfing, Dina; Wark, Michael; Brezesinski, Torsten; Smarsly, Bernd, M.; Rathousky, Jiri Adv. Funct. Mater. 2007, 17, 123-132.

(26) Crossland, E. J. W.; Kamperman, M.; Nedelcu, M.; Ducati, C.; Wiesner, U.; Smilgies, D. M.; Toombes, G. E. S.; Hillmyer, M. A.; Ludwigs, S.; Steiner, U.; Snaith, H. J. Nano Lett. 2009, 9, 2807 2812.

(27) Perlich, J.; Memesa, M.; Diethert, A.; Metwalli, E.; Wang, W.; Roth, S.; Timmann, A.; Gutmann, J. S.; Müller-Buschbaum, P. Phys. Status Solidi (RRL) 2009, 3, 118-120.
(28) Guldin, S.; Hüttner, S.; Tiwana, P.; Orilall, M. C.; Ulgut, B.; Stefik, M.; Kolle, M.; Divitini, G.; Ducati, C.; Redfern, S. A. T.; Snaith, H. J.; Wiesner, U.; Eder, D.; Steiner, U. submitted.

(29) Snaith, H. J.; Schmidt-Mende, L. Adv. Mater. 2007, 19, $3187-$ 3200.

(30) Nedelcu, M.; Lee, J.; Crossland, E. J. W.; Warren, S. C.; Orilall, M. C.; Guldin, S.; Huettner, S.; Ducati, C.; Eder, D.; Wiesner, U.; Steiner, U.; Snaith, H. J. Soft Matter 2009, 5, 134-139.

(31) Martinson, A.; McGarrah, J.; Parpia, M.; Hupp, J. Phys. Chem. Chem. Phys. 2006

(32) Crossland, E. J. W.; Nedelcu, M.; Ducati, C.; Ludwigs, S.; Hillmyer, M. A.; Steiner, U.; Snaith, H. J. Nano Lett. 2009, 9, 2813-2819.

(33) Alberius, P.; Frindell, K.; Hayward, R.; Kramer, E.; Stucky, G.; Chmelka, B. Chem. Mater. 2002, 14, 3284-3294.

(34) Allgaier, J.; Poppe, A.; Willner, L.; Richter, D. Macromolecules 1997, 30, 1582-1586

(35) Jiang, P.; Bertone, J.; Hwang, K.; Colvin, V. Chem. Mater. 1999, 11, 2132-2140.

(36) Miguez, H.; Ozin, G. A.; Tetreault, N. US Patent Application $11 /$ 878,023, 2007.

(37) Kuang, D.; Ito, S.; Wenger, B.; Klein, C.; Moser, J.; HumphryBaker, R.; Zakeeruddin, S.; Grtzel, M.J. Am. Chem. Soc. 2006, 128, 4146-4154.

(38) Nazeeruddin, M. K.; Zakeeruddin, S. M.; Humphry-Baker, R.; Jirousek, M.; Liska, P.; Vlachopoulos, N.; Shklover, V.; Fischer, C.H.; Gratzel, M. Inorg. Chem. 1999, 38, 6298-6305.

(39) Nedelcu, M.; Guldin, S.; Orilall, M. C.; Lee, J.; Huettner, S.; Crossland, E. J. W.; Warren, S. C.; Ducati, C.; Laity, P. R.; Eder, D.; Wiesner, U.; Steiner, U.; Snaith, H. J. J. Mater. Chem. 2010, 20, 1261-1268.

(40) Usami, A. Chem. Phys. Lett. 1997, 277, 105-108.

(41) Colodrero, S.; Mihi, A.; Haggman, L.; Ocana, M.; Boschloo, G.; Hagfeldt, A.; Miguez, H. Adv. Mater. 2009, 21, 764+

(42) Bach, U.; Lupo, D.; Comte, P.; Moser, J. E.; Weissrtel, F.; Salbeck, J.; Spreitzer, H.; Grtzel, M. Nature 1998, 395, 583-585.

(43) Halls, J. J. M.; Walsh, C. A.; Greenham, N. C.; Marseglia, E. A.; Friend, R. H.; Moratti, S. C.; Holmes, A. B. Nature 1995, 376, 498500 . 